\title{
Local and territorial determinants in the realisation of Public-Private- Partnerships: an empirical analysis for Italian provinces
}

Fabio Mazzola (Corresponding Author)

University of Palermo, Department of Economics, Business and Statistics, Viale delle Scienze, Building 13, Palermo, Italy.

E-mail: fabio.mazzola@unipa.it.

Alessandro Cusimano

University of Wolverhampton Business School, Department of Finance, Accounting, Systems and Economics, Arthur Storer (MN) Building, Wolverhampton, UK.

E-mail: a.cusimano@wlv.ac.uk.

Giuseppe Di Giacomo

Ministry of Economics and Finance, State General Accounting Department, Via XX

Settembre, 97, Roma, Italy.

E-mail: giuseppe.digiacomo@tesoro.it

Rosalia Epifanio

University of Palermo, Department of Economics, Business and Statistics, Viale delle

Scienze, Building 13, Palermo, Italy

E-mail: rosalia.epifanio@unipa.it

Fabio Mazzola is Full Professor of Economic Policy and Vice-Chancellor (Vice-Rector) at the University of Palermo, Italy. He holds a Ph.D. from the University of Pennsylvania, USA. He served as Dean of the Faculty of Economics at the University of Palermo from 2009 to 2013 and as Chairman of the Department of Economics, Business and Statistics in 2015. His international publications include policy evaluation, local economic development, regional macro-models, the locational aspects of innovation activity, the spatial effects of trade and economic integration, and the success conditions of firms in less developed areas. From 2013 to 2016 he served as President of AISRe (Italian Regional Science Association) and from 2016 to 2018 he has been a Councillor on the RSAI Board (Regional Science Association International) Council. He was the President of the Organising Committee of the 53rd European Regional Science Association Congress (Palermo, 2013). 
Alessandro Cusimano is a Lecturer in Economics at the University of Wolverhampton, UK. He holds a Ph.D. in Economics and performed research activity at the University of Kent, UK, and previously at the University of Palermo, Italy. His research interests include program evaluation, economic policy, and regional and spatial economics. He has recently published an article on ex-post evaluation of local development programs in "Scienze Regionali, Italian Journal of Regional Science". He has previously worked as a Teaching Associate in Economics at Lancaster University and as a Research Assistant and Teaching Assistant at University of Kent.

Giuseppe Di Giacomo is a public official at the Italian Ministry of Economy and Finance . He holds a Ph.D. from the University of Palermo. His publications cover local economic development, analysis and evaluation of public spending, policy evaluation and economics of education.

Rosalia Epifanio is Associate Professor of Applied Economics at the University of Palermo. She holds a Master's degree from the University of Sussex, UK, where she has performed further research activity. Her research interests include systems of innovation, local economic development and economics of cooperation, the main focus being the role of PMIs, human capital and innovation. She is component of the leading Research Unit of a national university research Project (PRIN 2017) on "A New Assessment of Cohesion Policies' Effectiveness: Macro And Micro Approaches”.

The paper is composed of 9,199 words including references. 


\title{
Local and territorial determinants in the realisation of Public-Private Partnerships: an empirical analysis for Italian provinces
}

\author{
Relational networks and intangible factors are crucial elements for the \\ competitiveness of a territory. Public-Private-Partnerships (PPPs), in particular, \\ allow for the provision of goods and services that favour the exploitation of \\ complementarities between public and private resources. They aim at promoting \\ an increase in the overall efficiency of investment projects through a complex \\ mechanism that distributes risk and revenues among stakeholders. This paper \\ examines the local and territorial determinants of PPPs through an econometric \\ analysis based upon Italian municipal data, grouped at provincial level. Using a \\ tobit model, we analyse the relationship between the realisation of successful PPP \\ initiatives and different sets of factors, including less analysed local and \\ territorial determinants. We stress the role of the local management of \\ infrastructure assets, the administrative efficiency of local authorities and the \\ diffusion of previous local development initiatives. Local management and \\ territorial context factors explain most of the occurrence of successful PPP \\ initiatives in the pre-crisis period while usual determinants (infrastructure \\ endowment and financial distress) display a weaker effect.
}

Keywords: Public-Private-Partnerships; territorial determinants; local assets; territorial capital; Italy

\section{Introduction}

The analysis of public-private-partnerships (PPPs) at territorial level has attracted growing attention over recent years, mainly because of the increasing interest of local authorities. The European Commission (2003) was among the first institutions to state that PPP initiatives could produce important benefits, including improvements in the quality of services offered, acceleration in the number of funding initiatives, minimisation of costs and, more generally, better stimulus to economic growth.

On a different ground, PPPs can be considered one of the elements of territorial capital. The latter represents a multi-dimensional analytical category that aims at encompassing 
several assets that influence a territory's competitiveness (OECD, 2001; European Commission, 2005). PPPs combine both material and non-material elements influencing forms of public-private cooperation for the production of goods and services with an intermediate degree of rivalry (Camagni, 2008).

With a specific focus on the Italian case, this paper aims at providing, on a provincial scale, an analysis of the factors determining the realisation of successful PPP initiatives among local administrations ${ }^{1}$. Such analysis has also implicit consequences for PPP planning strategies.

In detail there are two main research objectives that we aim at exploring.

The majority of existing studies have used as outcome measure the numbers of tenders. In our case, we focus on those initiatives that effectively took place. Indeed, we aim at testing if the causal relations between the realisation of PPP initiatives and the factors previously analysed in literature continue to hold when focusing only on the number of contracts really awarded instead of on the simple number of tenders. Therefore, as we will explain in detail later, we define two measures of positive outcomes related to PPPs and we use a tobit specification to relate the occurrence of realized PPP initiatives to a variety of local management and territorial context determinants.

In order to avoid the recent financial crisis distorting our estimations, we refer to the tenders launched between 2003 and 2007 resulting in contracts awarded within the first semester of 2009. The literature (see among other Kappeler and Nemoz, 2010) has highlighted that PPPs in Europe have considerably declined during the crisis period. They observe a similar pattern for many countries including Italy. Such evidence is 
strongly correlated with the worsening of the macroeconomic conditions during the Great Recession. In addition, the same literature shows that most of PPPs in Europe have a financial dimension over 10 million euros. For this reason we focus on these larger PPP initiatives since our aim is to highlight factors influencing projects that involve greater assets, a criterion which appears to be coherent with high financial investments. $^{2}$

A second research question concerns the specific factors that are considered into the analysis. Our goal is in this case to add into the analysis several local management and territorial context dimensions that can help to give a better comprehension of the role that local factors have in the positive occurrence of PPP initiatives vis-à-vis the determinants usually included in country-level studies. The importance of advanced management skills in local governments is highlighted in the literature as one of the main factors for the effectiveness of PPPs (Codecasa and Ponzini, 2011). This consideration would suggest to planners to devote considerable resources to the empowerment of public administrators.

In order to merge these two research objectives, we look at the effects on the number of initiatives that effectively took place of three subsets of factors that could explain the realisation of PPP initiatives by investigating separately the role of 'classical' and local management determinants as well as of some control variables reflecting the general economic and context conditions in the local area. Our findings are in line with some of the most recent literature concerning the Italian economy (Antellini Russo and

2 Larger projects tend to be more costly, leading to higher hidden and development costs, and the selection process is, in this case, stronger, thus determining a reduction of awards. Size is, therefore, an important element to take into account when examining actual completion of PPPs (Reeves et al., 2015). 
Zampino, 2012) in showing a weak relationship between the realisation of PPP initiatives and the infrastructural endowment, even when we use these new outcome measures. Furthermore, we find limited scope for the hypothesis that PPP initiatives are realised when the fiscal constraint is more effective. In contrast, we provide evidence of other local determinants of the diffusion of PPPs, such as the efficiency of local management and local economic conditions. These elements are, as far as we know, not usually considered in the scarce literature that focuses on PPP determinants at the subnational level ${ }^{3}$. We also find that a higher value added per capita and the existence of an active local entrepreneurial environment are positively correlated with the number of PPP initiatives that are actually awarded. Finally, a similar positive relationship is highlighted when we measure the social capital endowment of the area. As for bankruptcies, there appears to be an ambiguous impact of the overall credit conditions in the realisation of PPP initiatives. The paper is structured as follows: in the second section we review some of the most relevant literature on PPPs, summarising the different research objectives of the previous studies. In the third section we give an overview of the diffusion of PPPs in Italy and explain why we decided, in this work, to look at the situation before the financial and economic crises. In the fourth section we detail our model and in the fifth section we describe how we constructed the variables included in our analysis. Therefore we report and interpret our results and finally we draw our conclusions, providing some policy insights.

3 For instance, Albalate et al. (2015) found a significant result for fiscal variables and infrastructure endowments in an analysis of the determinants of PPPs at the local and state level in the US before 2008 but did not consider any explicit local and territorial explanatory variables in the analysis. 


\section{Literature review}

The use of PPPs has been boosted at an international level by recognition from the World Bank (2009), which includes PPPs among the 'new regional policies' and indicates them as a possible way of bridging the infrastructural endowment gap that is observed among different areas. Redmond (2008) believes that PPPs could be useful in reducing the infrastructure deficit in Ireland, but only if there is a sustained commitment at the policy and administrative levels. However, part of the literature empirically shows that the importance of this aspect diminishes when issues related to financial constraints of the public administration are considered (see, among others, Antellini Russo and Zampino, 2012).

A strong link between the decision to use PPPs and the financial strength of the local administration has been highlighted in most studies. As a pitfall of the Eurostat decision on the accounting treatment of PPPs (February 2004), the advantage of using PPPs has in fact been determined by limited budgets rather than by a drive for efficiency. From a theoretical point of view, Maskin and Tirole (2007) stated that 'there is substantial evidence that politicians' project choices are influenced significantly by the desire to please constituencies and by budgetary constraints' (p. 3). Akitoby et al. (2007) reported that 'PPPs allow governments to avoid or defer spending on infrastructure without forgoing its benefits.' (p. 9). Empirically, Hammami et al. (2006) showed, at a country level, how PPPs tend to be more diffuse in countries whose governments suffer from heavy debt burdens. Antellini Russo et al. (2010) and Antellini Russo and Zampino (2012) provided, at a provincial level, empirical evidence that, in Italy, the diffusion of PPPs tenders increase as public deficits worsen confirming the idea that some local administrations might employ PPP instrument in order to bypass financial 
and budget constraints ${ }^{4}$. However, other studies argue that in many circumstances the public budget constraints should not be able to explain the diffusion of PPPs (Engel et al., 2009; Engel et al., 2011 ${ }^{5}$ ).

The literature on PPPs has considerably grown in recent years. From the theoretical point of view, several studies aimed at determining when PPPs should be preferred over more traditional instruments ${ }^{6}$. Hodge and Greve (2007), for instance, claim that private finance enables governments to more easily shift resources to other policy priorities. It is common in the literature (see, among others, Steijn et al., 2011) to refer to the concept of Value for Money (VFM). This expression is commonly used to indicate 'the achievement, by a private or public organisation, of the best cost-benefit ratio of the acquisition of goods and/or services' (Antellini Russo and Zampino, 2012). Literature (among others Reeves, 2013, Regan et al., 2011, Albano and Antellini Russo, 2010, Grimsey and Lewis, 2007 and Grout, 2005) has already analysed this concept from many different perspectives and we will not add further on this aspect.

The existence and functioning of cooperation networks and PPPs appear to be influenced by local management variables that affect the success of these relationships. The local and territorial specificity of many assets determines the way in which current relationships and contracts are linked to existing or previous ones. As a matter of fact, PPP is more than just a contract, it requires the establishment of relationships, the

4 This phenomenon clearly increased with the explosion of the crisis because of the introduction of the so-called "Internal Stability Pact" which, starting from 2010, has imposed a constraint for the increase of expenditures by local administrations with respect to the previous year.

5 For more details see also Engel et al., 2014.

6 A theoretical model that shows when a government should use PPPs instead of conventional procurement is provided by Bentz et al., 2005. 
interaction between different competencies and skills, as well as market relationships. Such relational networks concern the interaction of government with businesses, of government with civil society and of business organizations with civil society (Lenferink et al., 2014). PPPs need the governance of organisations, including the relations between all the players that act in the public, private, local and regional domains (Bult-Spiering and Dewulf, 2006). In this sense, the asset specificity is dependent on the local pattern related to its physical and human characteristics. The presence of PPPs can also influence the formation of territorial capital, assuming that the private partner will contribute to the production of knowledge spillovers and the sharing of 'best practices' resulting in learning in the area where the PPP is located.

Local authorities and private investors are nowadays the key actors in the start-up and realisation of the PPP projects. The willingness of private contractors to invest their own capital is, to some extent, a positive signal for outside parties regarding the soundness of the project's economic planning (Leland and Pyle, 1977). In this way, problems are reduced and efficiency increases. Conversely, when a tender is not awarded, it might be argued that this happens because potential contractors do not trust the local authority.

Thus, PPP operations offer real economic advantages only when the synergies they produce as a result of integrating infrastructure and management in terms of overall efficiency are superior to the transaction and contractual costs correlated with this type of intervention. Nevertheless, many case studies have pointed out the risk of inaccuracies and optimism driven by the social-political relevance attributed to projects (Bult-Spiering and Dewulf, 2006).

Starting from the findings presented above, in the following sections, we focus on the different determinants of the realisation of PPP initiatives by investigating municipal 
data grouped at a provincial (NUTS 3) level. We aim, in the first instance, to test, with respect to the Italian case, the relevance of additional local and territorial factors that are less analysed in the literature. Furthermore, we aim at testing if the findings highlighted in the relevant literature are confirmed when new channels are added into the analysis and new outcome measures are considered. Our results show that local and territorial factors explain most of the occurrence of successful PPP initiatives. This allows us to provide some suggestions for infrastructure planning.

\section{Public-Private-Partnership evolution in Italy before and after the crisis}

The use of private capital in public procurement was initially developed in the United Kingdom where, in 1992, Private Finance Initiatives were launched. Thereafter, the growth of PPP contracts has been remarkable in Europe, the US and even developing countries (Iossa and Martimort, 2015). In Italy, the earliest PPPs were established at the beginning of the 1990s as part of the liberalisation process in the electricity sector; after that, the need for a framework to regulate partnerships between the public and private sectors became evident. The introduction of legislation in 1994 with the so-called 'Merloni Law' outlined the form of contract and defined the role of 'promoter'. Since then, the private sector has been able to participate in public procurements in partnership with public authorities.

Up until 2006, the rules were subject to various amendments and clauses when, eventually, the various laws on public negotiation were brought together, in conformity with EEC directives and rules stated in the Green book on PPPs (European Commission, 2004).

In this paper we focused on Italian PPP tenders realised between 2003 and 2007 resulting in contracts awarded between 2003 and the first semester of 2009. As 
previously mentioned, we chose not to focus on tenders made after 2007 since we did not want the results to be biased by the effects of the financial and sovereign debt crises. Indeed, if we were to consider a longer period, the relationship between the actual realisation of PPPs initiatives and the local management and territorial context dimensions would have been biased by the worsening of macroeconomic conditions following the Great Recession. For this reason, we preferred to concentrate our analysis on a period of relative macroeconomic stability in order to be more confident on the reliability of the causal relationship between our outcome measures and the local and territorial determinants. We also considered 18 months as a sufficient amount of time between the tender process and the award of the contract for investments that were not strongly affected by the explosion of the crisis ${ }^{7}$.

A further consideration relates to the standard of the participants to the PPPs tenders. In detail we believe that it cannot be stated ex-ante if the participants were of a higher or lower standard during the financial crisis. If, on the one hand, participants could be of a higher standard since they were more interested in obtaining a public contract, on the other hand also the opposite effect could be true: lower standard private companies, being more in need of funds because of the financial crisis, could have decided to apply for a PPP tender. Also for this reason, we preferred to focus on the pre-crisis period given that the inclusion of post-crises years might distort the effects of our estimations. PPPs have been increasing constantly since 2002, both in number and in the financial size of tenders. Osservatorio Nazionale Project Financing (2011) and, more recently, the data gathered by IFEL-Fondazione Anci (2017) reported that this expansion has been

7 In their analysis on the determinants of the length of the tendering period in the U.K., Reeves et al. (2017) estimate the minimum and average tendering periods as 8 and 35 months, respectively. 
remarkable, with the number of tenders at the municipality level increasing from 264 in 2002 to more than 2400 in 2016 and amounts increasing from half a billion euros in 2002 to more than 4 billion euros in 2016 (Table 1).

Large projects mainly concern the transportation sector (especially local public transportation) and utilities, particularly in the northern and central regions of Italy.

\section{(TABLE 1 AROUND HERE)}

However, the trend is not the same if we focus on the number of those initiatives that effectively took place. Data reported in Table 1 show that the latter (number of awarded contracts) are in 2016 at a level similar to 2009 , compared to the number of tenders, which almost doubled. This is in line with the trend reported, at the European level, by Kappeler and Nemoz, 2010 for the first year of the crisis period. From a different perspective, the majority of PPP contracts involved local infrastructure with low technical complexity, predictable cash flows and limited risks, such as car parks, cemeteries and sports facilities.

It is well known that PPPs can be classified depending upon their sources of revenues. Concession models refer to projects with an intrinsic capacity to produce income since most of the private contractors' revenues are from consumption (motorways, sports facilities, cemeteries). In project financing activities, on the contrary, the private partner earns its revenues from service provision to public authorities (for example the construction and management of schools, prisons, hospitals).

In order to carry out a more accurate analysis of the phenomenon, we focused, in our study, on larger PPP initiatives (over 10 million euros) where the PPPs include a contractual relationship in which there is a combination of construction and 
management phases. As previously discussed, the choice of this threshold is due to the consideration that most of PPPs initiatives were over 10 million euros in the pre-crisis period and in the crisis years. In addition, adopting a 10 million threshold, our analysis is comparable with investigations concerning the majority of the other European countries.

Columns 1-3 of Table 2 display the ranking of the first ten Italian provinces in terms of number of tenders and the respective success rate, defined as the ratio between positive outcomes and total number of invitations. On average, the success rate at the national level was 0.26 .

The majority of the ten provinces with the highest number of initiatives were in the South. Spearman's rank correlation coefficient between the number of invitations for proposals and success rate showed a low correlation (0.35). Therefore, more active cities in terms of tenders appeared to be the least 'efficient' when we refer to the success rate $^{8}$.

If we concentrate only on the success rate and restrict the analysis to provinces with at least three invitations, the ranking shows that the relative effectiveness of provinces in northern and central Italy is higher (columns 4-6). With the exception of Taranto, the ten most efficient provinces were, in fact, located in these areas.

\section{(TABLE 2 AROUND HERE)}

With regard to the types of projects financed, most of the PPP initiatives in Italy involved 'healthcare' (16.66\%), followed by 'car parks' (16.16\%) and 'water,

8 This phenomenon also depends on the efficiency of the administrative process, which is strictly related to the length of the tendering period. Competition may be reduced even if there is a perception of inefficiency by potential private investors. 
electricity, gas, telecommunications' (14.65\%). Transport initiatives, which belong to the concession models category, appeared to be less relevant than expected (7.56\%) and awards were only made in a few cities. 'Urban environment and public parks' (1.01\%), 'infrastructure for recreation' $(0.5 \%)$ and 'tourism' $(0.5 \%)$ were at the bottom of the rankings, representing only a small percentage of all PPPs.

Kappeler and Nemoz (2010) reported that among large European PPP projects (more than 5 million euros), transport initiatives were dominant. Healthcare, on the contrary, had a low incidence in the European context. For both these sectors, therefore, the Italian trend appears to be at odds with the European scenario. This difference might be owing to a different role played by the local management and territorial context in explaining the positive outcome of initiatives and this is what we will mainly investigate in the remaining part of our work.

\section{Local and territorial determinants of PPPs: the explanatory model}

To analyse the role of local and territorial factors in influencing PPPs in Italy, we proceeded to estimate a tobit model on the likelihood of realising PPP initiatives. As previously mentioned, our first research objective consists in focusing on the tenders that found at least one interested bidder and resulted in awarded contracts. Indeed this outcome measure captures in a better way the effectiveness of PPP initiatives within a specific area. The underlying hypothesis is that there is a latent variable $\mathrm{y}^{*}$, corresponding to the profitability of a PPP initiative, influenced by various factors; these include the characteristics of the local authority that issues the invitation and also local context variables promoting or hampering this specific category of investments. In particular, in order to extend the factors potentially able to explain the realisation of PPP initiatives in an area we distinguish three subsets of factors. 
The first subset consists of two variables already analysed by the relevant literature that we may refer as the 'classical' determinants. They include:

- The local infrastructure endowment, since we should suppose the existence of a positive relationship between the infrastructural gap and the realisation of PPP initiatives (see, among others, World Bank, 2009, and Antellini Russo and Zampino, 2012).

- The financial strength of municipalities, since local administrations with higher fiscal revenues might be less inclined towards using PPPs (see among others, Akitoby et al., 2007; Maskin and Tirole, 2007; Hammami et al., 2006 and, for Italy, Antellini Russo et al., 2010).

We consider, in addition, a second subset of variables capturing some indicators of efficiency of local management which are usually not explicitly considered in the PPP literature at the local level. They include:

- The effectiveness of the municipality management involved in reducing the infrastructure gap through investment. We would expect that some municipalities will be more effective in closing the infrastructure gap through investment and that such municipalities will have a higher success rate in the completion of the tendering procedure (European Commission, 2003). On the other hand, the number of tenders may tend to increase when municipalities are less effective in closing the infrastructure gap with their own resources. As previously stressed, in this paper, we look at the number of tenders that found at least one interested bidder and resulted in awarded contracts. Therefore, the direction of the effect of this variable is, in principle, ambiguous since both the number and the success are important for the definition of the outcome measure. 
- The administrative efficiency of local management with respect to municipal spending, since we would expect that more efficient administrations should be involved in a lower number of PPP initiatives.

- The ability of local management to promote an endogenous local growth process, as we may assume that local administrations tend to adopt new financing tools for infrastructure when they more accustomed to promoting local development initiatives.

Finally, a third subset of variables is added to our analysis to control for the macroeconomic and context characteristics of the area. They include:

- The level of GDP per capita, as a measure of economic development of the area. In alternative specifications we included the level of GDP, which mainly acts as a general indicator of the size of the area. Both these variables should reasonably relate positively with the realisation of PPP initiatives.

- The overall density of firms in the area, since it is reasonable to believe that the higher the number of firms, the higher the likelihood that invitations launched in the municipality would find an adequate response from the private sector.

- The overall credit conditions, for which the direction of the impact is ambiguous, because, on the one hand, bankruptcies signal the existence of credit rationing but, on the other, a higher number of bankrupt firms could reflect a better functioning of the market mechanism.

- The social capital endowment of the area. As a possible measure of social capital, we introduce the "Voice and Accountability" dimension of the Institutional Quality Index (Nifo and Vecchione, 2014). We expect, ex-ante, a positive relationship with the outcome variables considered. 
From the methodological point of view, the model used for the empirical estimate is a standard tobit bounded from below at 0 for the dependent variable. The choice of the model is owing to the characteristics of the dependent variable (number of invitations with awarded contracts), which is equal to zero for a relevant number of provinces.

Defining PPP_Outcomes* as the non-observed latent variable, it is assumed that when it has negative values the PPP initiative does not take place. The observed variable, named PPP_Outcomes, has zero value when PPP_Outcomes* is negative, while it is equal to PPP_Outcomes* when positive. Then:

$$
\begin{aligned}
& \text { PPP_Outcomes }{ }_{i}^{*}=X_{i} \beta+\varepsilon_{i} \quad \text { with } i=1,2, \ldots, N \\
& \text { PPP_Outcomes }{ }_{i}=P P P_{-} O \text { Outcomes }{ }_{i}^{*} \quad \text { when PPP_Outcomes }{ }_{i}^{*}>0 \\
& \text { PPP }_{\text {Outcomes }_{i}}=0 \quad \text { when PPP } \text { Outcomes }_{i}{ }^{*} \leq 0
\end{aligned}
$$

where the subscript $i$ indicates the observed values for each $i$ province (NUTS3), $X$ is the vector of explanatory variables and $\varepsilon$ is a normally distributed error term. Therefore, defining single explanatory variables, the base model to be estimated is the following:

$$
\begin{aligned}
& \text { PPP_Outcomes }{ }_{i}^{*}=\beta_{0}+\beta_{1}(\text { Infr_End })+\beta_{2}(\text { Mun_rev })+\beta_{3}(\text { Infr_Eff })+ \\
& +\beta_{4}(\text { Mun_eff })+\beta_{5}(\text { Loc_Dev })+\beta_{6}(G D P p c)+\beta_{7}(\text { Firms })+\beta_{8}(\text { Credit })+ \\
& \beta_{9}\left(\text { Soc_Cap_End }_{-}\right)+\varepsilon_{i}
\end{aligned}
$$

where Infr_End is the infrastructure endowment, Mun_Rev is an indicator that measures the incidence of municipal revenues, Infr_Eff is an indicator of effectiveness in closing the infrastructure gap, Mun_Eff is an index of municipal efficiency, Local_Dev is a variable that captures the capacity of the local administration to realise local 
development initiatives, GDPpc is the GDP per capita, Firms is an index of entrepreneurship density, Credit is an indicator of availability of credit in the area and Soc_Cap_End is a proxy for the endowment of social capital. ${ }^{9}$

\section{Data description}

Data on PPPs are obtained through the construction of an unique dataset,by merging information contained in the Italian Observatory on Project Financing ${ }^{10}$ with information inferred by the OICE/Informatel Observatory. In our analysis, we use data for the tenders realised between 2003 and 2007 resulting in awarded contracts between 2003 and the first semester of 2009.

As mentioned above, we consider initiatives corresponding to awards worth over ten million euros (the aggregation is at province or NUTS 3 level) In order to verify whether a significant relationship exists between the infrastructure gap and the number of assignments, we considered an index of general infrastructure endowment (source: Istituto Tagliacarne) for the year 2001 (Infr_End).. This index appears to be suitable for our analysis because it includes both economic and social infrastructure, thus encompassing almost all activities conducted in $\operatorname{PPPs}^{11}$.

An index of fiscal pressure (Mun_Rev) was also introduced; it is calculated as the logarithm of the provincial average of municipalities' fiscal revenues per capita in the period 2003-2007 (source: ISTAT, municipality balance sheets).This decision was

9 In some specifications, a slightly different version of equation 3 has been used. This has been detailed in the Results section.

10 Italian Observatory on Project Financing contains information on all initiatives related to public-private partnerships at the municipality level.

11 Tagliacarne's index was chosen in preference to other infrastructure indices used in Italy (Messina, 2008; Di Palma and Mazziotta, 2002). 
made with the intention of verifying the availability of financial assets and of quantifying the potential distortion in promoting PPPs as an accounting tool for moving public expenditure 'off the balance sheet' 12 .

Moving to the subset of local management determinants, an index reflecting the effectiveness of the municipality management involved in reducing the infrastructure gap (Infr_Eff) was also added to the analysis(source: Picci, 2002). . The higher the index, the lower is the result in terms of infrastructure endowment relative to the amount of investments undertaken. This is usually the case in southern Italy and bigger cities. $^{13}$

In addition, an administrative efficiency index of municipal spending was included, aggregated at a provincial level (Mun_Eff). Budget data relative to municipalities with more than 5,000 inhabitants (source: ISTAT, municipality balance sheets) were used to construct this index. In particular, the efficiency scores of local authorities were calculated by estimating a relative efficiency frontier using the non-parametric DEA statistic method (Data Envelopment Analysis) with variable returns and input orientation. The municipalities on the efficiency frontier thus constitute the standard for evaluating the others and they were assigned an efficiency score of 1 . In line with the literature concerning the efficiency of local authorities (De Borger and Kerstens, 1996; Afonso and Fernandes, 2005; Boetti et al., 2012), a single input was used to represent the total current expenditure of the municipalities, while there were 15 outputs

12 It was not possible to refer to municipality fiscal sheets for previous years because they referred to the pre-euro period. This introduces a potential endogeneity problem, which is discussed in footnote 15 .

13 The financial expenditure on infrastructure is obtained through the perpetual inventory method. More details on the construction of the index can be found in Picci, 2002. The index of infrastructure endowment is taken from Di Palma and Mazziotta (2002). 
corresponding to the indicators used for measuring individual applications for services provided by the municipalities. Both inputs and outputs were derived from final balance sheets ${ }^{14}$. We included all the indicators representing profits earned by the municipalities for providing services as well as the number of requests met and the number of services and structures offered to the public. Indicators regarding the number of employees, the total direct cost and potential demand (applications made) of specific utilities were not considered. In this way, the output indicators cover the 12 macro-functions that make up current expenditure in a fairly homogeneous manner. Once efficiency scores for each municipality had been calculated, we proceeded to aggregate them on a provincial basis (for each province) calculating a weighted average where the weights are the number of inhabitants in each municipality.

The efficiency indicator calculated in this way represents a proxy of each municipality's capacity to produce a certain amount of output efficiently, i.e. reducing to a minimum (in relative terms) the financial resources employed. In this respect, while taking into account the fact that a part of the output indicators captures the capacity of local authorities to self-finance a service with the profits earned, it seems likely that the most efficient municipalities have fewer financial constraints. It is therefore interesting to hypothesise and to verify empirically whether this greater financial capacity results in less need for PPP initiatives.

The number of local development initiatives promoted at the provincial level (Local_Dev) was included in the model in order to quantify the relationship between the

14 For this variable and the previously defined index of fiscal pressure we are aware of a potential risk of reverse or simultaneous causality. Therefore, in order to mitigate it, we estimated an OLS regression of each of these two variables on both our outcome measures but we did not find any statistical evidence of reverse causality. However, we are aware that the approach adopted could be potentially not sufficient to exclude the risk. 
expertise gained by the local government in the start-up and management phases of PPP initiatives and the trust attributed by private investors. Trebilcock and Rosenstock (2015), indeed, stress the institutional capacity as one of the main determinants of PPPs success since these initiatives are usually complex and they require to anticipate and foresight contingencies that are unknown at the beginning of the tendering process. To build up this variable, the following initiatives were considered: PRUSST (source: Ministry of Infrastructure and Transportation, National Account of Infrastructure and Transportation), Urban I and II (European Commission, 2003b), Patti territoriali, Contratti di programma, and Leader I and II (source: Ministry of Economic Development, Annual Reports). These initiatives were mostly launched before the period of our analysis.

For the macroeconomic and territorial context variables, a first control included in the model is the GDP per capita (GDPpc, source: ISTAT), in some specifications substituted by total provincial GDP. Both variables have been calculated as the average from 2000 to 2003. In addition, we included the entrepreneurship density (Firms), defined as the logarithm of the annual average of the number of active firms divided by the municipalities area from 2000 to 2003 (source Unioncamere-Movimprese), indicating the vitality of the local economic environment where PPPs are undertaken. The availability of credit (Credit) is considered in the model by using the logarithm of the 2002-2003 average of the number of bankrupt firms with respect to the total number of active firms (per 10,000 firms) in the province (source: Unioncamere-Movimprese). Finally, as an indicator of social capital endowment the component "Voice and Accountability" of the Institutional Quality Index was used for 2004(source: Nifo and Vecchione, 2014).This includes, among others, Associations, Social cooperatives and Election participations. We also considered Crime as an indirect indicator of social 
capital. In fact, its impact on PPP initiatives is a-priori ambiguous, as we could expect, on the one hand, that criminal activity does not encourage the diffusion of PPPs but that, on the other, PPPs might become themselves attractive activities for existing organised crime. The literature (Albanese et al., 2015) has showed an interesting non monotonic inverse-U shaped relationship between central public procurement and crime measures. However, in our case, the inclusion of crime may cause misleading interpretations as crime could itself be a partial result of the social capital endowment. Therefore, we decided not to include this variable into the analysis.

Descriptive statistics for the explanatory variables used are provided in Table 3 . The latter shows a different variability among the local indicators included as they are calculated according to the different metrics detailed above. In Table A.1 of the Appendix we show evidence of the partial correlation coefficients across the explanatory variables.

\section{(TABLE 3 AROUND HERE)}

\section{Results and interpretation}

In our analysis, we focused on two main outcome measures. Our first outcome variable is constituted by the number of tenders that found at least one bidder interested and resulted in awarded contracts (Positive Outcomes). In detail, we focused on all the tenders realised between 2003 and 2007 resulting in awarded contracts between 2003 and the first semester of 2009. A further consideration deals with the fact that Italian provinces are quite different in terms of size. Therefore, we also aimed at determining if our results were confirmed when we take into consideration the territorial dimension more explicitly. Consequently, we considered as an alternative outcome variable the 
ratio between the positive outcomes of PPPs and the area of provinces (in $\mathrm{km}^{2}$ ) and estimated a tobit model by looking at the impact of the previous variables on this different outcome measure (Positive Outcomes/Provincial Area). Table 4 shows the descriptive statistics of the two outcome measures under investigation.

\section{(TABLE 4 AROUND HERE)}

Table 5 shows the first estimation of the tobit model regarding the realisation of PPP initiatives across 103 Italian provinces. ${ }^{15}$ As mentioned above, for most of the data the series are constructed by aggregating municipality data. Our first outcome measure is constituted by the number of tenders that found at least one interested bidder and resulted in awarded contracts.

\section{(TABLE 5 AROUND HERE)}

Model 1 represents our general specification as detailed in equation (3). If we look at the impact of the classical determinants on the positive outcomes of PPPs, we notice that, with respect to the infrastructure endowment, the expected negative sign was obtained, confirming what is reported by some literature (see, among others, Redmond, 2008). However the magnitude of the effect seems very small, as suggested by more recent contributions (Antellini Russo et al., 2012). The other classical motivation for PPP, namely the need for a financial alternative during a period of tight budgets, was

15 In Tables 5 and 6, robust standard errors have been estimated using Huber/White/sandwich estimator. 
found to be ineffective. ${ }^{16}$. These findings lead us to think that other dimensions may be more suitable for explaining the diffusion of PPPs and for this reason we concentrate now on local management and territorial context determinants.

In this group the variable expressing the effectiveness of local management in reducing the infrastructure gap (Infr_Eff) shows a positive impact on the dependent variable. Therefore the lower infrastructure endowment relative to the amount of investments undertaken (and indicator of less infrastructure effectiveness at the municipal level) acts as an important driver in successfully promoting PPPs.. In line with this result, the impact of the variable Mun_Eff appears to be negative and statistically significant, showing the dependence of PPP on the authority's capacity to provide services cheaply. Third, the number of local development initiatives (Loc_Dev) is positive and statistically significant, showing that the capacity to promote local development initiatives indicates greater activity on the part of the local authority and, consequently, a greater capacity to promote innovative projects.

Moving to the third group of explanatory variables that control for the general economic and territorial context conditions in the local area, the positive and statistically significant effect of the GDP per capita and the number of active firms (Firms) show that greater dynamism and diffusion of the entrepreneurial environment is positively correlated with the number of PPP initiatives that are awarded. Similar considerations hold for the positive and statistical significant impact of the social capital endowment. We also found a lack of statistical significance in the variable Credit. Indeed, the higher number of bankruptcies seems to be related with greater diffusion of PPPs, which may

16 Geddes and Wagner (2013) in an analysis of the motivation for PPPs in the US found little evidence that states' fiscal constraint as measured by fiscal health (debt outstanding) is an important driver in the decision to introduce PPP regulations. 
be explained by the argument that higher diffusion of PPPs occurs in areas where the market mechanisms work better. One additional consideration on Model 1 relates to the high correlation between some of the macroeconomic and context characteristics of the area ( in particular the proxy for the social capital endowment and the GDP per capita) and the indicators of efficiency for local management. ${ }^{17}$ Therefore in Model 2 and Model 3 we check if our results are confirmed when we exclude, in turns, GDP per capita and social capital endowment. The results seem robust to this exclusion.

In model 4 of the same table, we provide an alternative specification where we include, among the explanatory variables that control for the general economic and territorial context conditions in the local area, the average of the GDP at the provincial level ${ }^{18}$. The inclusion of this variable is motivated by the need to control explicitly for the size of the province. The estimation of this alternative specification confirms the general low significance of the classical determinants of PPPs and the relative importance of local management determinants, in particular, municipality and infrastructure efficiency. In contrast, the coefficient for local development initiatives loses significance though it remains close to it. A larger economic dimension of a province would, indeed, lead to a higher absolute number of development programs thus reducing their ceteris paribus effect on the probability of awarding PPP initiatives. Among the control variables, GDP level, firm density and social capital appear to confirm their importance while credit conditions confirm their irrelevance in the diffusion of PPP initiatives.

Given the well-known dualistic structure of the Italian economy, we took into account the macro region in which the province is located to see if the outcome of PPP would in

17 This is reported in Table A.1 in Appendix.

18 This means that we need to remove the GDP per capita from the subset of our classical controls. 
some way be related to that characteristic. For this reason, we include in model 5 of table 5 a dummy variable (Dummy South), which assumes a value equal to 1 if the province is localised in the South and 0 otherwise. The results show that the geographical location of the provinces does not seem to have a specific differential effect on the diffusion of PPPs ${ }^{19}$. This is because the model already includes many explanatory variables for which the South is less endowed. In other words, the Southern specificity is already taken into account through the macro-regional variability of many variables in the model $^{20}$.

Finally, in model 6, we restrict our estimation only to the variables that are statistically significant. Results are confirmed both in terms of the size and magnitude of the effects. Moreover, the statistical significance is very similar to the general specification previously reported.

The next step consists of determining if our results are confirmed when we take into consideration the territorial extension of Italian provinces. As previously explained, we considered as an alternative outcome variable the ratio between the positive outcomes of PPPs and the area of provinces (in $\mathrm{km}^{2}$ ) and estimated a tobit model by looking at the impact of the previous variables on this new outcome measure (Positive Outcomes/Provincial Area). Results are provided in Table 6 where Model 1 is constructed according to the same structure of Table 5. Since for some of the variables the magnitude of the coefficient becomes, in this case, very small, we consider Model 2,

19 Such result is in line with the one obtained by Antellini Russo and Zampino (2012) since the South displays a higher percentage of tenders but a lower percentage of PPP initiatives that are actually completed.

20 Indeed, a negative high correlation does exist between the South dummy and many variables of the model (municipal revenues, municipal efficiency, local development, per capita GDP and social capital). 
where we include the variables Infr_End and Loc_Dev in logs. In this case, we lost seven observations and excluded provinces for which the number of local development initiatives promoted was zero. In Model 3 and Model 4 of Table 6, as we did for the previous outcome variable, we check if our results are confirmed when we exclude, in turns, GDP per capita and social capital endowment. Also in this case the results seem robust to this exclusion. In Model 5, we include the South dummy and in Model 6 we restrict our estimations only to the variables that are significant.

\section{(TABLE 6 AROUND HERE)}

Overall, the results provide robustness to our previous findings. ${ }^{21}$ Apart from the variable local development ( $\left.L o c_{-} D e v\right)$, for which the coefficient turned out to be not significant, all the previous results are confirmed. In addition, the impact of infrastructural endowment turns out to be not significant, in line with the results of Antellini Russo et al. (2012). The smaller magnitude of the effects is related to how the new outcome measure has been defined, now being in relative terms with respect to the provincial areas.

\section{Further considerations and discussion}

All our estimates are consistent in showing that the infrastructural endowment itself (Infr_End) cannot explain the diffusion of PPPs. This result is quite relevant and perfectly in line with the most recent empirical literature previously mentioned. The

\footnotetext{
${ }^{21}$ Similar results, not reported for brevity, are obtained by considering, as an alternative outcome variable, the ratio between the positive outcomes of PPPs and population of provinces.
} 
importance of local management and territorial context was found both with respect to the positive relationship of the variable Infr_eff with both the outcome measure considered and with respect to the negative impact of municipality efficiency (Mun_eff) and provides empirical evidence that a greater management ability appears to be a negative driver for the diffusion of PPPs.

Indeed, our findings confirm that municipalities with an efficient administration tend to be involved in a lower number of PPP initiatives since they are likely to be able to provide services in other ways that they perceive as cheaper. This conclusion deserves a deeper reflection. It could be argued that more efficient municipalities could rely on more skilled officers, potentially able to deal with complex projects such as PPPs. However, if on the one side this is true, on the other side officers could not have the specific and complex skills required to deal with PPPs. In addition, more efficient management could prefer to control and manage the separate arrangements of a traditional public procurement scheme instead of bundling them in a single contract as a PPP. Finally we should acknowledge that the literature (see among others Grimsey and Lewis, 2007), considers the possibility of transferring the risk to the private sector as an advantage of PPPs. However this point may be less relevant in a framework where public officers often look at short run objectives, and therefore could not perceive the full advantage of this risk transfer.

The positive and significant coefficient of the variable GDP per capita was also expected. Moreover, the expected and positive sign is confirmed for the firm density and the social capital endowment variables. The low significance of the number of bankruptcies (Credit) coefficient shows, instead, the possibility of a counterintuitive effect, as discussed while commenting Table 5. It appears that the final specification 
includes all the relevant variables for which Southern provinces are less endowed and that no other relevant Southern peculiarity is left to be taken into account.

\section{Conclusions}

In the present paper, we analysed the determinants of the realisation of PPP initiatives at a local level and focused the potential role of local management and territorial context determinants in promoting the diffusion of PPPs. In Italy, before the Great Recession, in the period under observation, there has been a strong increase in the number of PPPs for financing infrastructures and local public services. After the crisis, even if the number of tenders seemed to increase constantly, the trend in actually awarded contracts showed an inverse U-shaped pattern. A similar situation was observed in most of other European countries. Therefore, our research objective is to determine the factors that explain the realisation of successful PPP initiatives in Italy, focusing in particular on local management and territorial context characteristics and looking at those initiatives that effectively took place. Overall, as a general outcome, the role of meta-economic and non-traditional locally characterised factors in PPP initiatives is confirmed (Trumbull, 2009).

It emerged that the use of such initiatives cannot be linked alone to the need to bridge existing infrastructure gaps, as highlighted by previous literature (Antellini Russo and Zampino, 2012). In addition, the budget constraints of local administrations do not seem to be able to explain the diffusion of PPPs (Engel et al., 2009; Engel et al., 2011).

At the same time, when we look at the impact of the effectiveness in infrastructure investment and of the administrative efficiency of municipalities on the diffusion of PPPs, we provide empirical evidence that more efficient administrations are involved in fewer PPP initiatives. This conclusion, quite new in the literature, looks particularly 
interesting and may be explained by considerations related with the skill capacity, desire for control and risk attitude of municipal administrators.

Overall, we believe that the reported significant impact of different local management and territorial context determinants on the realisation of PPP initiatives and the joint consideration of their effect together with some more traditional factors represent a useful set of tools for the policy maker and an important improvement with respect to the previous literature. Local policymakers should therefore make better use of PPPs according to the circumstances and concentrate more on the overall administrative efficiency, thus restricting the utilisation of the instrument to the cases in which the solidity of the institutional network and the dimension of the investment would require such a procedure. In any case, a careful cost-benefit analysis should precede the launch of these operations. These results could be particularly useful for policymakers and suggest that adequate planning should be put in place to monitor PPP initiatives and strengthen mechanisms favouring transparency and legality, and to control the promotion and implementation of tools of cooperation between the public and private sectors in order to avoid any distortion of the purposes and benefits of such tools. In particular, three sets of arguments will be relevant for infrastructure planning. First, a specific empowerment program for local administrators is strategic in developing PPPs since, on the one hand, very complex skills are required in this activity and, on the other, a sub-optimal level of ability of local managers would let them to prefer more traditional procurement schemes and overlook the advantages of PPP initiatives. Second, the familiarity with handling local development programs is important because PPP builds upon the endowment of territorial capital and the continuity in planning development initiatives at local level can help to diffuse PPP schemes. Third, the overall level of social capital is related with the development of successful PPP initiatives. 
Therefore, infrastructure planning schemes through PPP financing should pursue collaboration among stakeholders starting from the early phases with an increasing involvement of the civil society.

Finally, our work has a few limitations that we want to mention. We did not look at the different characteristics of the PPPs in terms of type, sectors and time of negotiation and award. Furthermore, we concentrate on the municipal level and do not compare the determinants of PPP across different territorial levels. In addition, it would be very interesting to look at the differential effect of the financial and economic crises on the diffusion of PPPs. We leave these objectives for future research.

\section{Acknowledgements}

The authors acknowledge the support in data collection by Giada Cuticchio in the early stages of the paper.

The authors would like to thank the anonymous referee and the Editor for the helpful comments received.

\section{Funding}

Financial support by the Italian Ministry of Education, University and Research (MIUR) through the Fund for Research Projects of National Interest (PRIN) is gratefully acknowledged. 


\section{References}

Afonso, A., and S. Fernandes, 2005, "Local government spending efficiency: DEA evidence for the Lisbon Region”, Regional Studies 40(1) 39-53.

Albalate, D., G. Bel, and R.R. Geddes, 2015, “The determinants of contractual choices for private involvement in infrastructure projects, Public Money and Management, $35(1), 87-94$.

Akitoby, B., R. Hemming, and G. Schwartz, 2007, "Public Investment and PublicPrivate Partnerships", International Monetary Fund, Economic Issues 40.

Albanese, G., F. Antellini Russo, and R. Zampino, 2015, "Criminalità e scelte degli amministratori locali in tema di procedure di acquisto". Banca d'Italia - Questioni di Economia e Finanza, 294.

Albano G., and F. Antellini Russo, 2010 "Politica infrastrutturale e Partenariato Pubblico Privato. La centralizzazione come strumento per l'efficienza delle scelte pubbliche". MEF, Quaderni Consip.

Antellini Russo F., Giamboni L., and R. Zampino, 2010, "Il partenariato pubblicoprivato come escamotage?" Società Italiana di Economia Pubblica, Conference proceedings. Pavia 20-21 September.

Antellini Russo F., and R. Zampino, 2012, "Infrastructures, Public Accounts and Public-Private Partnerships: Evidence from the Italian Local Administrations" Reviews of Economics and Institutions: $3,1$.

Bentz A., Grout P., and M. Halonen, 2005, "What Should Governments Buy from the Private Sector-Assets or Services?" Mimeo, University of Bristol. 
Boetti L., Piacenza M., and G. Turati, 2012, "Decentralization and Local Governments'Performance: How Does Fiscal Autonomy Affect Spending Efficiency?" FinanzArchiv: Public Finance Analysis, Mohr Siebeck, Tübingen, vol. 68(3), 269-302, September.

Bult-Spiering M., and G. Dewulf, 2006, "Strategic Issues in the Public-Private Partnerships: An International Perspective”, Oxford, Blackwell.

Camagni R., 2008, "Regional Competitiveness: Towards a Concept of Territorial Capital”, in Modelling Regional Scenarios for the Enlarged Europe, 33-47, edited by Camagni R, Capello R., Chizzolini B. and U,.Fratesi , Springer.

Codecasa G., and D. Ponzini, 2011, "Public-Private Partnership: A Delusion for Urban Regeneration? Evidence from Italy" European Planning Studies, 19 (4), 647-667

De Borger B., and K. Kerstens, 1996, "Cost efficiency of Belgian local governments: A comparative analysis of FDH, DEA, and econometric approaches" Regional Science and Urban Economics 26 (2) 145-170.

Di Palma M., and C. Mazziotta, 2002, "La dotazione di capitale pubblico in Europa e in Italia: un quadro di riscontri empirici”, in L'Italia nella Competizione Globale Regole per il Mercato, edited by Baldassarri M., Galli G. And G. Piga, Milano, Edizioni il Sole 24 Ore.

Engel E., Fischer R., and A. Galetovic, 2014, "The Economics of Public-Private Partnerships: A Basic Guide". Cambridge: Cambridge University Press.

Engel E., Fischer R., and A. Galetovic, 2011, "Public-Private Partnerships and infrastructure provision in the United States". Documentos de Trabajo 277, Centro de Economía Aplicada, Universidad de Chile. 
Engel E., Fischer R., and A. Galetovic, 2009, "Public-Private Partnerships: When and How" Documentos de Trabajo 257, Centro de Economía Aplicada, Universidad de Chile.

European Commission, 2003, “Guidelines for successful public-private partnerships". http://europa.eu.int/comm/regional_policy/sources/docgener/guides/PPPguide.htm.

European Commission, 2004, “Green paper on public-private partnerships and Community law on Public-Private Partnerships And Community Law On Public Contracts and Concessions”. (COM), 2004, 327.

European Commission, 2005, "Territorial State and Perspectives of The European Union. Scoping document and Summary of Political Messages”. Bruxelles.

Geddes R.R., and B.L. Wagner (2013), "Why do U.S. states adopt public-private partnership enabling legislation", Journal of urban Economics, 78, November, 30-41

Grimsey D., and M. Lewis, 2007, "Public Private Partnerships and Public Procurement", Agenda: 4, 2, 171-188.

Grout P., 2005, "Value-for-money measurement in public-private partnerships", EIB (European Investment Bank) papers, vol.10, n.2 p.32-57

Guccio, C., Pignataro G., and I. Rizzo, 2014, "Do local governments do it better? Analysis of time performance in the execution of public works". European Journal of Political economy, 34, 237-252

Hammami, M., Ruhashyankiko J., and E. Yehoue, 2006, "Determinants of PublicPrivate Partnerships In Infrastructure", International Monetary Fund working paper 06/99. 
Hodge G., and C. Greve, 2007, "Public-Private Partnerships: An International Performance Review”. Public Administration Review, vol 67, issue 3: 545-558.

IFEL-Fondazione Anci 2017, "La dimensione comunale del partenariato pubblicoprivato", Edizione 2017-Studi e Ricerche.

Iossa, E., and F. Antellini Russo, 2008, "Potenzialità e criticità del Partenariato Pubblico-Privato in Italia”, Rivista di Politica Economica, 5-6, 125-158.

Iossa E., and D. Martimort, 2015 "The simple microeconomics of public-private partnerships", Journal of Public Economic Theory, 17 (1), 2015, 4-48.

Kappeler A., and M. Nemoz, 2010, "Public-Private Partnership in Europe - before and during the recent financial crisis". Economic and Financial Report 2010/04. European Investment Bank.

Leland, H. E., and D.H. Pyle, 1977, "Informational Asymmetries, Financial Structures, and Financial Intermediation” Journal of Finance 32, 371-387.

Lenferink S., Leendertse W., Arts J. and T. Tillema, 2014, "Public-Private Plan Development: Can Early Private Involvement Strengthen Infrastructure Planning?, European Planning Studies, 22:2, 323-344.

Maskin E., and J. Tirole, 2008, "Public-private partnerships and government spending limits", International Journal of Industrial Organization. 2008; 26 (2) :412-420.

Messina G., 2008, "Un nuovo metodo per misurare la dotazione territoriale di infrastrutture di trasporto". Dossier Unione europea - Studi e Ricerche, n. 3.

Nifo A., and G. Vecchione, 2014, "Do Institutions play a role in skilled migration? The case of Italy", Regional Studies, 48,10: 1628-1649

OECD, 2001, OECD Territorial Outlook, Paris. 
Osservatorio Nazionale Project Financing, 2011, "Dieci anni di partenariato pubblico privato in Italia - Sintesi”, Cresme Europa Servizi.

Picci L, 2002, “Le infrastrutture in Italia, Le differenze territoriali e l'efficienza della spesa', in L'Italia nella Competizione Globale - Regole per il Mercato, edited by Baldassarri. M., G.Galli, and G.Piga G., Milano: Edizioni il Sole 24 Ore.

Redmond T., 2008, "Are the public private partnerships the solution to the Ireland's infrastructure deficit?" $3^{\text {rd }}$ International Public Procurement Conference Proceedings.

Reeves E., 2013, "The not so good, the bad and the ugly: over twelve years of PPP in Ireland" Local Government studies, 39:3, 375-395.

Reeves E., Palcic D., and D. Flannery, 2015, “PPP Procurement in Ireland: An Analysis of Tendering Periods", Local Government Studies, 41 (3), 379-400.

Reeves E., Palcic D., Flannery D., and R.R. Geddes, 2017 "The determinants of tendering periods for PPP procurement in the UK: an empirical analysis". Applied Economics. Vol.49: 1071-1082.

Regan, M., J. Smith, and P. Love, 2011, "Infrastructure procurement: learning from private-public partnership experiences 'down under'” Environment and Planning C: Government and Policy 29, 2, $363-378$.

Steijn B, Hans Klijn E., and J. Edelenbos, 2011, "Public-private partnerships: added value by organizational for or management?" Public Administration, vol.89, n.4 (1235-1252).

Trebilcock M., and M. Rosenstock. 2015, "Infrastructure Public-Private Partnerships in the Developing World: lessons from recent experience", The Journal of Development Studies, 51, 4 ,335-354. 
Trumbull N., 2009, "Fostering private - public partnerships in the transition economies:

HELCOM as a system of implementation review" Environment and Planning $C$ : Government and Policy 27, 5, $858-875$.

World Bank, 2009, World development report, Reshaping Economic Geography.

\section{(APPENDIX AROUND HERE)}


Table 1: Tenders and awarded contracts at municipality level from 2002 to 2016

\begin{tabular}{|c|c|c|c|c|c|}
\hline Year & $\begin{array}{c}\text { Number of } \\
\text { Tenders }\end{array}$ & $\begin{array}{c}\text { Financial } \\
\text { Dimension (in } \\
\text { million euros) }\end{array}$ & $\begin{array}{c}\text { Number of } \\
\text { awarded } \\
\text { contracts }\end{array}$ & $\begin{array}{c}\text { Financial } \\
\text { Dimension (for } \\
\text { awarded } \\
\text { contracts in } \\
\text { million euros) }\end{array}$ & $\begin{array}{c}\text { Ratio of } \\
\text { Awarded } \\
\text { contracts }\end{array}$ \\
\hline 2002 & 264 & 575 & 78 & 134 & 0.30 \\
\hline 2003 & 407 & 1219 & 108 & 443 & 0.27 \\
\hline 2004 & 664 & 908 & 189 & 669 & 0.28 \\
\hline 2005 & 832 & 1780 & 320 & 1423 & 0.38 \\
\hline 2006 & 624 & 3553 & 200 & 1260 & 0.32 \\
\hline 2007 & 761 & 1441 & 240 & 1740 & 0.32 \\
\hline 2008 & 1024 & 1602 & 400 & 1470 & 0.39 \\
\hline 2009 & 1558 & 1542 & 489 & 1545 & 0.31 \\
\hline 2010 & 2478 & 2262 & 601 & 1520 & 0.24 \\
\hline 2011 & 2307 & 4960 & 736 & 3435 & 0.32 \\
\hline 2012 & 2562 & 1469 & 586 & 3104 & 0.23 \\
\hline 2013 & 2338 & 1589 & 690 & 1785 & 0.30 \\
\hline 2014 & 2293 & 2223 & 530 & 945 & 0.23 \\
\hline 2015 & 2621 & 4096 & 491 & 1484 & 0.19 \\
\hline 2016 & 2483 & 4070 & 495 & 1533 & 0.20 \\
\hline
\end{tabular}

Source: IFEL-Fondazione Anci calculations on Italian observatory on Project Financing 
Table 2 - Ranking of Italian provinces by number and by success rate of PPP invitations greater than 10 million Euros (2003-2007, outcomes until I semester 2009)

Ranking by number of tenders

Ranking by success rate

\begin{tabular}{|c|c|c|c|c|c|}
\hline Province & $\begin{array}{c}\text { Number of } \\
\text { tenders }\end{array}$ & $\begin{array}{l}\text { Success } \\
\text { rate }\end{array}$ & Province & $\begin{array}{c}\text { Number of } \\
\text { tenders }\end{array}$ & $\begin{array}{c}\text { Success } \\
\text { rate }\end{array}$ \\
\hline Naples & 52 & 0.25 & Taranto & 3 & 1 \\
\hline Rome & 50 & 0.18 & Brescia & 6 & 0.83 \\
\hline Milan & 43 & 0.44 & Turin & 12 & 0.75 \\
\hline Palermo & 30 & 0.07 & Latina & 8 & 0.75 \\
\hline Caserta & 27 & 0.26 & Novara & 7 & 0.71 \\
\hline Catania & 26 & 0.31 & Gorizia & 3 & 0.67 \\
\hline Salerno & 25 & 0.08 & Pisa & 3 & 0.67 \\
\hline Bari & 21 & 0.24 & Venice & 8 & 0.63 \\
\hline Genoa & 20 & 0.20 & Mantova & 5 & 0.60 \\
\hline Trapani & 18 & 0.33 & Modena & 9 & 0.56 \\
\hline
\end{tabular}

Source: Our calculations on Italian Observatory on Project Financing data 
Table 3: Descriptive statistics of explanatory variables

\begin{tabular}{|c|c|c|c|c|c|c|c|c|c|c|}
\hline & Infr_End & Mun_Rev & Infr_ Eff & Mun_Eff & $\begin{array}{c}\text { Local_ } \\
\text { Dev }\end{array}$ & $G D P p c$ & $G D P$ & Firms & Credit & $\begin{array}{c}\text { Soc_Cap_ } \\
\text { End }\end{array}$ \\
\hline Mean & 98.40 & 14.96 & 113.00 & 0.44 & 6.31 & 0.02 & 12799.60 & 2.72 & 2.98 & 0.41 \\
\hline $\begin{array}{c}\text { Standard } \\
\text { Deviation }\end{array}$ & 66.70 & 0.24 & 93.63 & 0.14 & 5.45 & 0.01 & 18362.41 & 0.72 & 0.37 & 0.18 \\
\hline Minimum & 24.65 & 14.46 & 34.73 & 0.19 & 0.00 & 0.01 & 1519.25 & 1.26 & 1.67 & 0.00 \\
\hline Maximum & 549.11 & 15.40 & 801.19 & 0.89 & 28.00 & 0.04 & 132001.50 & 5.16 & 3.94 & 1.00 \\
\hline
\end{tabular}


Table 4: Descriptive statistics of the outcome variables

\begin{tabular}{|c|c|c|c|c|}
\hline & Mean & $\begin{array}{c}\text { Standard } \\
\text { Deviation }\end{array}$ & Minimum & Maximum \\
\hline Positive Outcomes & 1.9612 & 2.9636 & 0 & 19 \\
\hline $\begin{array}{c}\text { Positive } \\
\text { Outcomes/Provincial Area }\end{array}$ & 0.0090 & 0.0016 & 0 & 0.0111 \\
\hline
\end{tabular}


Table 5 - Determinants of awarded PPP initiatives (Outcome variable: Positive Outcomes)

\begin{tabular}{|c|c|c|c|c|c|c|}
\hline Variable & Model 1 & Model 2 & Model 3 & Model 4 & Model 5 & Model 6 \\
\hline Constant & $\begin{array}{c}-3.3868 \\
(-0.17) \\
\end{array}$ & $\begin{array}{r}-7.0389 \\
(-0.35)\end{array}$ & $\begin{array}{c}-19.7639 \\
(-0.95)\end{array}$ & $\begin{array}{l}-3.9189 \\
(-0.24)\end{array}$ & $\begin{array}{r}-3.8389 \\
(-0.20)\end{array}$ & $\begin{array}{c}-11.4872 * * * \\
(-5.01)\end{array}$ \\
\hline Infr_End & $\begin{array}{c}-0.0122 * * \\
(-2.56)\end{array}$ & $\begin{array}{c}-0.0135 * * * \\
(-3.04)\end{array}$ & $\begin{array}{l}-0.0080 \\
(-1.31)\end{array}$ & $\begin{array}{c}-0.0074^{*} \\
(-1.79)\end{array}$ & $\begin{array}{c}-0.01215 * * \\
(-2.56)\end{array}$ & $\begin{array}{c}-0.01242 * * \\
(-2.50)\end{array}$ \\
\hline Mun_Rev & $\begin{array}{c}-0.6398 \\
(-0.47)\end{array}$ & $\begin{array}{c}-0.2735 \\
(-0.20)\end{array}$ & $\begin{array}{c}0.5096 \\
(0.36)\end{array}$ & $\begin{array}{c}-0.0634 \\
(-0.06)\end{array}$ & $\begin{array}{c}-0.6179 \\
(-0.46)\end{array}$ & \\
\hline Infr_Eff & $\begin{array}{c}0.01547 * * * \\
(4.73)\end{array}$ & $\begin{array}{c}0.0136 * * * \\
(4.38)\end{array}$ & $\begin{array}{c}0.0123 * * * \\
(3.54)\end{array}$ & $\begin{array}{c}0.0091 * * * \\
(3.61)\end{array}$ & $\begin{array}{c}0.0154 * * * \\
(4.75)\end{array}$ & $\begin{array}{c}0.0158 * * * \\
(4.71)\end{array}$ \\
\hline Mun_eff & $\begin{array}{c}-7.8245 * * * \\
(-3.11)\end{array}$ & $\begin{array}{c}-5.1157^{*} \\
(-1.91)\end{array}$ & $\begin{array}{c}-8.6241 * * * \\
(-2.89)\end{array}$ & $\begin{array}{c}-5.4256^{* *} \\
(-2.40)\end{array}$ & $\begin{array}{c}-7.8211 * * * \\
(-3.11)\end{array}$ & $\begin{array}{c}-8.0223 * * * \\
(-3.26)\end{array}$ \\
\hline Loc_Dev & $\begin{array}{c}0.1952^{* * *} \\
(2.88)\end{array}$ & $\begin{array}{c}0.1516 * * \\
(2.30)\end{array}$ & $\begin{array}{c}0.2375 * * * \\
(3.35)\end{array}$ & $\begin{array}{c}0.0641 \\
(1.21) \\
\end{array}$ & $\begin{array}{c}0.1925 * * * \\
(2.65)\end{array}$ & $\begin{array}{c}0.2093 * * * \\
(3.17)\end{array}$ \\
\hline$G D P p c$ & $\begin{array}{c}245.2693 * * * \\
(2.67) \\
\end{array}$ & & $\begin{array}{c}223.21 * * * \\
(4.39)\end{array}$ & & $\begin{array}{c}249.9811^{* *} \\
(2.49) \\
\end{array}$ & $\begin{array}{c}246.8314 * * * \\
(2.60)\end{array}$ \\
\hline$G D P$ & & & & $\begin{array}{c}0.0001 * * * \\
(3.01)\end{array}$ & & \\
\hline Firms & $\begin{array}{c}1.7697 * * * \\
(2.75)\end{array}$ & $\begin{array}{c}2.1759 * * * \\
(3.35)\end{array}$ & $\begin{array}{c}2.1643 * * * \\
(2.91)\end{array}$ & $\begin{array}{c}1.1922 * \\
(1.93)\end{array}$ & $\begin{array}{c}1.7349 * * \\
(2.53)\end{array}$ & $\begin{array}{c}1.8853 * * * \\
(3.08)\end{array}$ \\
\hline Credit & $\begin{array}{c}0.5606 \\
(0.57)\end{array}$ & $\begin{array}{c}0.7301 \\
(0.71)\end{array}$ & $\begin{array}{c}-0.1257 \\
(-0.11)\end{array}$ & $\begin{array}{c}0.1929 \\
(0.22)\end{array}$ & $\begin{array}{c}0.5824 \\
(0.57)\end{array}$ & \\
\hline Soc_Cap_End & $\begin{array}{c}9.4582 * * * \\
(3.19)\end{array}$ & $\begin{array}{c}12.4892 * * * \\
(4.40)\end{array}$ & & $\begin{array}{c}6.9962 * * * \\
(3.04)\end{array}$ & $\begin{array}{c}9.5421 * * * \\
(3.11)\end{array}$ & $\begin{array}{c}9.0111 * * * \\
(2.95)\end{array}$ \\
\hline Dummy South & & & & & $\begin{array}{c}0.1484 \\
(0.13) \\
\end{array}$ & \\
\hline $\mathrm{N}$ & 103 & 103 & 103 & 103 & 103 & 103 \\
\hline $\begin{array}{l}\text { Log } \\
\text { pseudolikelihood }\end{array}$ & -170.24 & -173.57 & -177.60 & -164.42 & -170.23 & -170.52 \\
\hline Prob>F & 0.0000 & 0.0000 & 0.0000 & 0.0000 & 0.0000 & 0.0000 \\
\hline Pseudo $R^{2}$ & 0.1938 & 0.1780 & 0.1590 & 0.2214 & 0.1939 & 0.1925 \\
\hline
\end{tabular}

Note: ***: significant at $1 \%$; **: significant at $5 \%$; *: significant at $10 \%$. T-statistics in parentheses. 
Table 6 - Determinants of awarded PPP initiatives (Outcome measure: Positive

Outcomes/Provincial Area)

\begin{tabular}{|c|c|c|c|c|c|c|}
\hline Variable & Model 1 & Model 2 & Model 3 & Model 4 & Model 5 & Model 6 \\
\hline Constant & $\begin{array}{r}0.0066 \\
(0.65)\end{array}$ & $\begin{array}{r}-0.0021 \\
(-0.22)\end{array}$ & $\begin{array}{r}-0.0044 \\
(-0.46)\end{array}$ & $\begin{array}{c}-0.0094 \\
(-0.98)\end{array}$ & $\begin{array}{r}-0.0004 \\
(-0.04)\end{array}$ & $\begin{array}{c}-0.0048 * * * \\
(-5.80)\end{array}$ \\
\hline Infr_End & $\begin{array}{c}-1.39 \mathrm{e}-06 \\
(-0.69)\end{array}$ & $\begin{array}{c}-0.0006 \\
(-1.42)\end{array}$ & $\begin{array}{l}-0.0007 \\
(-1.59)\end{array}$ & $\begin{array}{c}-0.0002 \\
(-0.53)\end{array}$ & $\begin{array}{c}-0.0006 \\
(-1.39)\end{array}$ & \\
\hline Mun_Rev & $\begin{array}{c}-0.0008 \\
(-1.10)\end{array}$ & $\begin{array}{l}-0.0001 \\
(-0.12)\end{array}$ & $\begin{array}{l}0.0001 \\
(0.19)\end{array}$ & $\begin{array}{c}0.0004 \\
(0.54)\end{array}$ & $\begin{array}{l}-0.0002 \\
(-0.25)\end{array}$ & \\
\hline Infr_Eff & $\begin{array}{c}1.24 \mathrm{e}-05^{* * * *} \\
(7.43)\end{array}$ & $\begin{array}{c}1.19 \mathrm{e}-05^{* * * *} \\
(7.74)\end{array}$ & $\begin{array}{c}1.14 \mathrm{e}-05^{* * * *} \\
(7.50)\end{array}$ & $\begin{array}{c}1.05 \mathrm{e}-05^{* * * *} \\
(6.13)\end{array}$ & $\begin{array}{c}1.20 \mathrm{e}-05^{* * * *} \\
(8.23)\end{array}$ & $\begin{array}{c}1.12 \mathrm{e}-05 * * * \\
(7.17)\end{array}$ \\
\hline Mun_eff & $\begin{array}{c}-0.0030 * * * \\
(-2.65)\end{array}$ & $\begin{array}{c}-0.0030 * * * \\
(-2.71)\end{array}$ & $\begin{array}{c}-0.0022 * * \\
(-2.03)\end{array}$ & $\begin{array}{c}-0.0034 * * * \\
(-2.63)\end{array}$ & $\begin{array}{c}-0.0030 * * * \\
(-2.74)\end{array}$ & $\begin{array}{c}-0.0034 * * * \\
(-2.97)\end{array}$ \\
\hline Loc_Dev & $\begin{array}{c}-9.06 \mathrm{e}-06 \\
(-0.34)\end{array}$ & $\begin{array}{c}8.71 \mathrm{e}-05 \\
(0.50)\end{array}$ & $\begin{array}{c}2.74 \mathrm{e}-05 \\
(0.16)\end{array}$ & $\begin{array}{c}0.0002 \\
(1.11)\end{array}$ & $\begin{array}{c}0.0001 \\
(0.70)\end{array}$ & \\
\hline$G D P p c$ & $\begin{array}{c}0.0723 * \\
(1.76)\end{array}$ & $\begin{array}{c}0.0729 * \\
(1.75)\end{array}$ & & $\begin{array}{c}0.1543 * * * \\
(3.16)\end{array}$ & $\begin{array}{l}0.0591 \\
(1.31)\end{array}$ & $\begin{array}{c}0.0715^{* * *} \\
(1.99)\end{array}$ \\
\hline Firms & $\begin{array}{c}0.0009 * * * \\
(3.41)\end{array}$ & $\begin{array}{c}0.0012 * * * \\
(3.71)\end{array}$ & $\begin{array}{c}0.0013 * * * \\
(4.11)\end{array}$ & $\begin{array}{c}0.0013 * * * \\
(3.27)\end{array}$ & $\begin{array}{c}0.0013 * * * \\
(3.90)\end{array}$ & $\begin{array}{c}0.0008 * * * \\
(3.56)\end{array}$ \\
\hline Credit & $\begin{array}{c}-2.75 e-05 \\
(-0.06)\end{array}$ & $\begin{array}{c}-0.0001 \\
(-0.18)\end{array}$ & $\begin{array}{c}2.61 \mathrm{e}-05 \\
(0.06)\end{array}$ & $\begin{array}{c}-0.0005 \\
(-0.90)\end{array}$ & $\begin{array}{c}-0.0001 \\
(-0.29)\end{array}$ & \\
\hline Soc_Cap_End & $\begin{array}{c}0.0043 * * * \\
(3.48)\end{array}$ & $\begin{array}{c}0.0040 * * * \\
(3.27)\end{array}$ & $\begin{array}{c}0.0049 * * * \\
(3.97)\end{array}$ & & $\begin{array}{c}0.0038 * * * \\
(2.83)\end{array}$ & $\begin{array}{c}0.0039 * * * \\
(3.52)\end{array}$ \\
\hline Dummy South & & & & & $\begin{array}{c}-0.0004 \\
(-0.93)\end{array}$ & \\
\hline $\mathrm{N}$ & 103 & 96 & 96 & 96 & 96 & 103 \\
\hline $\begin{array}{l}\text { Log } \\
\text { pseudolikelihood }\end{array}$ & 315.51 & 299.50 & 298.04 & 292.94 & 299.82 & 313.10 \\
\hline Prob $>F$ & 0.0000 & 0.0000 & 0.0000 & 0.0000 & 0.0000 & 0.0000 \\
\hline Pseudo $R^{2}$ & -0.1965 & -0.2117 & -0.2058 & -0.1852 & -0.2130 & -0.1874 \\
\hline
\end{tabular}

Note: ***: significant at 1\%; **: significant at 5\%; *: significant at $10 \%$. T-statistics in parentheses. 
Appendix - Table A.1 - Partial correlation matrix between explanatory variables

\begin{tabular}{|c|c|c|c|c|c|c|c|c|c|c|c|}
\hline & $\begin{array}{c}\text { Infr_E } \\
\text { nd }\end{array}$ & $\begin{array}{c}\text { Mun_Re } \\
\mathrm{v}\end{array}$ & Infr_Eff & Mun_Eff & Loc_Dev & GDPpc & GDP & Firms & Credit & $\begin{array}{c}\text { Soc_Cap_ } \\
\text { End }\end{array}$ & Dum South \\
\hline Infr_End & 1.000 & & & & & & & & & & \\
\hline Mun_Rev & 0.315 & 1.000 & & & & & & & & & \\
\hline Infr_Eff & 0.267 & -0.247 & 1.000 & & & & & & & & \\
\hline Mun_Eff & 0.077 & 0.488 & -0.392 & 1.000 & & & & & & & \\
\hline Loc_Dev & -0.138 & -0.463 & 0.238 & -0.417 & 1.000 & & & & & & \\
\hline GDPpc & 0.238 & 0.587 & -0.384 & 0.639 & -0.514 & 1.000 & & & & & \\
\hline GDP & 0.226 & 0.173 & 0.239 & 0.092 & 0.115 & 0.438 & 1.000 & & & & \\
\hline Firms & 0.580 & 0.297 & 0.345 & 0.082 & -0.159 & 0.343 & 0.532 & 1.0000 & & & \\
\hline Credit & 0.262 & -0.010 & 0.370 & -0.060 & 0.160 & -0.011 & 0.362 & 0.461 & 1.000 & & \\
\hline Soc_Cap_End & 0.332 & 0.5284 & -0.346 & 0.462 & -0.344 & 0.745 & 0.423 & 0.323 & -0.074 & 1.000 & \\
\hline Dum South & -0.116 & -0.5013 & 0.521 & -0.5248 & -0.5404 & -0.717 & -0.071 & 0.014 & 0.119 & -0.641 & 1.000 \\
\hline
\end{tabular}

